\title{
Research on Effective Teaching Strategies in Flipped Classroom
}

\author{
Jing Chang \\ Institute of Information Scienc and Technology Guangdong University of Foreign Studies South \\ China Business College, Guangdong, Guangzhou 510545, China \\ hapipingye@163.com
}

\begin{abstract}
As a new teaching mode of information technology, the flipped classroom provides a new way for the reform of classroom teaching in Colleges and universities. The study of this paper shows that the flipped classroom is conducive to creating a harmonious learning atmosphere, inducing and maintaining learning motivation, stimulating learning autonomy, helping students to construct knowledge, promoting the development of students' ability and improving the learning satisfaction. However, flip the classroom for students' self-learning ability, input learning time, the teacher's teaching quality, the support of learning resources have a higher requirements.
\end{abstract}

Keywords: Flipped Classroom; Effectiveness; Teaching strategies.

\section{Introduction}

"Flipped classroom" is a new type of teaching mode which is produced in recent years, which is supported by information technology. In the flipped classroom, students in the classroom to watch the micro video instead of the teacher's classroom to explain, to complete the practice and the classroom with teachers, students discussion, collaboration, communication [1].It completely subvert the traditional teaching process to impart knowledge, extra-curricular teaching mode of internalization of knowledge, to change the "transfer - accept" teaching methods. The traditional single teaching mode has been difficult to meet the requirements of personnel training, turning the classroom as a new teaching mode, to provide a new path for the reform of classroom teaching in Colleges and universities.

Flipped classroom is divided into before class, class and after class three links, before the class knowledge transfer, knowledge in class and after class knowledge recovery [2].Before the study of the carrier is mainly micro video, video length, video content, visual effect is an important factor. Using interactive software Catalytic [3] Learning, can be produced for students to discuss the teaching of video, the use of text, pictures, 3D animation and video digital interactive teaching materials instead of teaching video. Learning activities in the class are rich, independent learning, collaborative inquiry, but also based on the project, the game, the problem of learning, the creation of problem situations, problems, put forward the hypothesis, verify the hypothesis, solve the problem is the basic link. The creation of the problem situation is aimed at students to produce cognitive conflict, the desire to explore, the method of creating problem situation is operable. Classes also ensure that students have enough time to conduct autonomous learning, teachers as a helper, guide and service providers, to support students to solve the problem. In the flipped classroom to increase the class link, so that teachers carry out the course summary and develop the next round of plans.

\section{Implementation Strategy}

Based on flipped classroom teaching theory, instructional design theory, based on the problem of learning theory, the teaching strategy of flipped classroom teaching was preliminarily constructed. In the flipped classroom teaching design, the development of micro video, self-study guide book, self-evaluation table and group cooperation learning evaluation form, provided in a timely manner to the students, and through the works before class, before class list, class assignments, self-evaluation questionnaire, cooperative learning evaluation table of observation and analysis, and teacher interviews reflection on action research process, strategy of modified and perfect. 
Before the class, the students read the self-study guide book, watch the micro video, independent exploration, complete the task, to stimulate doubt, upload work, feedback and characterization of the problem. Before class, students' autonomous learning and exploration is the process of continuous knowledge practice, knowledge and practice. It is the process of the problem and the characterization of the problem in the contradiction between the completion of the task and the limited knowledge. In the class, the class to share, to explore the situation of the problem, and then to explore, to solve the situation of the problem, the final display of work, to show the problem of thinking, evaluation, summary of knowledge and problem-solving process. In the classroom, students use collective resources to solve problems. Through the transition to the situation, the students can make the students aware of the nature of the problem. After class is also before the class, students through the process of self-reflection of knowledge and problem solving process, improve the ability to solve problems. In the course of evaluation and summary of the link is different, after class students pay more attention to their knowledge of the master, ability to obtain the situation, and the lesson is concerned as a model of the problem solving thinking. Flipped classroom question guiding strategies include teachers guide problem solving strategy and the student participate in the problem solving strategy. Teachers through the preparation of self-guide books, micro video, the use of software tools, the deployment of time, organize groups to learn and guide teaching and learning. Students answer questions by writing the key words, to participate in cooperative learning, rational use of time, and evaluation of learning.

\section{The Effectiveness of The Flipped Classroom Teaching}

"Effectiveness" means the degree to which an activity has reached the expected result [4].The effectiveness of the flipped classroom refers to the extent to which the expected results are achieved through a series of teaching activities during the course of the flipped classroom teaching. It is not only to pay attention to the general characteristics of the flipped classroom and the traditional teaching, but also pay more attention to the teaching effect which cannot be achieved by turning the classroom in the end. The intended effect of the flipped classroom should focus on pay close attention to the following aspects: to create a harmonious learning atmosphere, inducing course interest in learning, stimulate their learning autonomy, promote cognitive learning, development of exchanges and cooperation ability, and improve the learning satisfaction.

With the students "learning" as the center, before class students to use micro class, teaching resources learning basic knowledge. In class mainly adopts "Exhibition on the achievements and problem discussion, case analysis, learning experience, answer questions, debate and discussion enhance explanation" and other learning activities teaching. The important problem of classroom research by the teacher before class through the interaction of the network, teachers and students in extra-curricular interaction is the main way of curriculum group; group learning before class to "line based, online supplemented" [5].

Before the course of the teaching process as shown in figure 1:

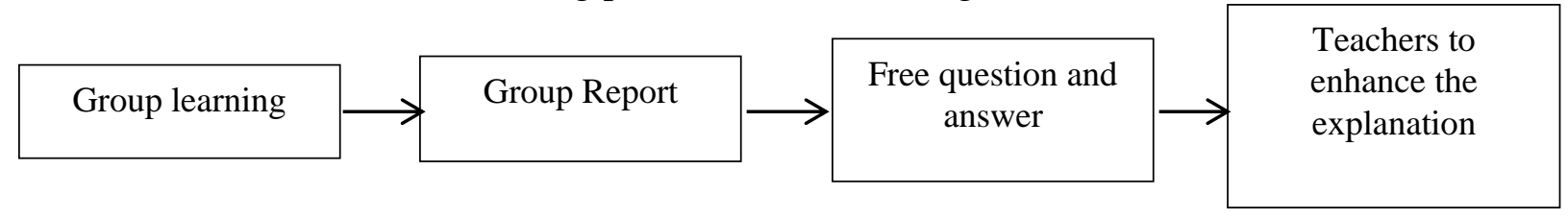

Fig. 1 before the course of the teaching process

The teaching process in the class is shown in Figure 2:

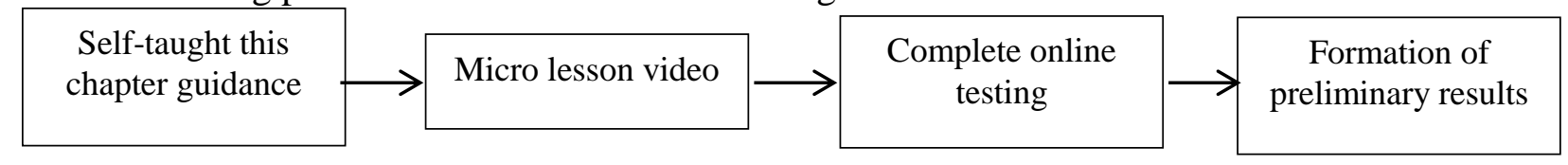

Fig. 2 teaching process in the class 
After class teaching process as shown in figure 3:

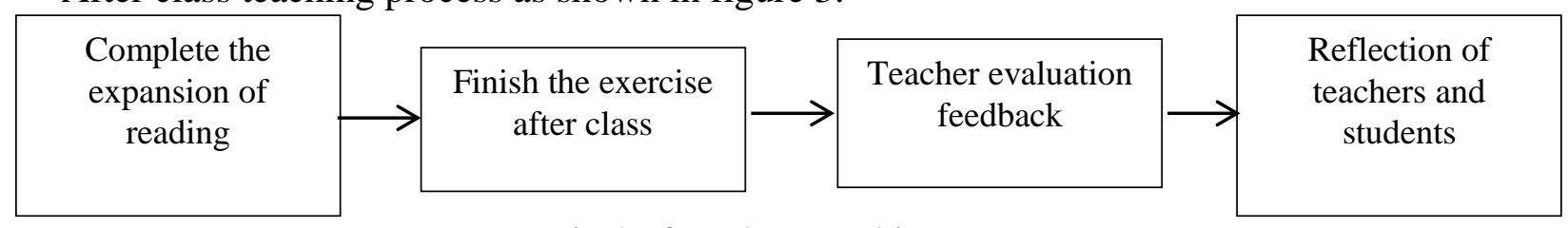

Fig. 3 after class teaching process

Flipped classroom teaching seems to reduce the knowledge, in fact, flip the classroom teaching quality of teachers put forward higher requirements, teachers in the flipped classroom is also far more than the traditional teaching [6].It is not an easy thing to effectively carry out the flipped classroom. The flipped classroom in the learning activities of students as the center, design of learning resource, teaching process design, learning activity design, organization of classroom activities, learning process evaluation and other aspects are the focus of, any link omissions may cause global failure. The frequent interaction of students and teachers and students in the flipped classroom break the boring classroom atmosphere and set up an active classroom atmosphere and a good relationship between teachers and students. Student's fierce debate, improvisation play, fun experience, collision sparks, dynamic generation greatly mobilize their interest in learning, improve the students' learning satisfaction. Active learning activities can cultivate students' autonomous learning ability, cooperative learning ability, self-presentation ability and language expression ability.

\section{Conclusion}

Compared with the traditional classroom, flipped classroom to exchange and share instead of the traditional teaching mode, the exchange ability of learners, communication skills and cooperation ability are beneficial. As a kind of new teaching mode, the traditional teaching structure, teaching method and teaching mode are turned over, and the teaching mode of "taking the students as the center" is established. In this mode, the students really become the subject of study, and the teacher is the organizer, helper and guide of the students' learning. In spite of the flipped classroom has a lot of advantages, but in the implementation process, on teachers and teaching environment design have many requirements, need the teacher to carry on more systematic instructional design and impose more effective management and control of teaching activities.

\section{Acknowledgments}

"A Model Program for Cultivating the Applied Talents of Computer Science and Technology" under the 2015 Undergraduate Teaching Quality and Teaching Reform Project in Guangdong Province (Document No. [2015] 133 issued by the Department of Education of Guangdong Province concerning higher education)

\section{References}

[1] Xie Jing, Ni Miaoshan, Bai Jing, et al. Integration of flipped classroom and MF College MOOCs teaching mode [J]. China audio visual education, 2015, (10): 40-46.

[2] Wang Caixia, Liu Guangran. An analysis of the optimization of the classroom teaching of the secondary vocational education in the classroom teaching [J]. Vocational Education Forum, 2013, (6): 41-44.

[3] Things You Should Know About Flipped Classrooms [DB/OL].http://

[4] neteducause, edu/ir/library/pdf/ELI7081.pdf,2012-08-20.

[5] Wang Jianhua. The effectiveness of classroom teaching and its reasonable application [A]. Shandong Normal University. National first teaching theory Doctoral Forum thesis collection [C]. Ji'nan: Shandong Normal University, 2015.154-165. 
[6] Pan Bingchao. Quasi experimental study on the effect of the flipped classroom on college teaching effect [J]. Modern education, 2014, (12): 84-91.

[7] Li Xin. Study on the evaluation system of the teaching quality of flipped classroom -- learning from the evaluation standard of CDIO teaching mode $[\mathrm{J}]$. Audio visual education research, 2015, (3): 96-99. 